\title{
Erratum to: Multi-objective component sizing of plug-in hybrid electric vehicle for optimal energy management
}

\author{
Vahid Madanipour $^{1} \cdot$ Morteza Montazeri-Gh $^{1} \cdot$ Mehdi Mahmoodi-k $^{1}$
}

Published online: 11 June 2016

(C) Springer-Verlag Berlin Heidelberg 2016

\section{Erratum to: Clean Techn Environ Policy DOI 10.1007/s10098-016-1115-1}

Unfortunately, the co-author's affiliation was published incorrectly in the original publication of the article. The corrected affiliation is given in this erratum.

The online version of the original article can be found under doi:10.1007/s10098-016-1115-1.

Vahid Madanipour

v.madanipour@gmail.com

1 Systems Simulation and Control Laboratory, School of Mechanical Engineering, Iran University of Science and Technology, Tehran, Iran 